\title{
Pancreaticoportal fistula in association with antiphospholipid syndrome presenting as ascites and portal system thrombosis
}

\author{
Li-Hsin Chang MD, Luc Francoeur MD FRCP, Franzjosef Schweiger MD FRCP FACP FACG
}

L-H Chang, L Francoeur, F Schweiger. Pancreaticoportal fistula in association with antiphospholipid syndrome presenting as ascites and portal system thrombosis. Can J Gastroenterol 2002;16(9):601-605.

Fistulous communication between the pancreas and the portal venous system is extremely rare and is usually a complication of chronic pancreatitis or pancreatic pseudocysts. A patient who presented with abdominal pain and ascites secondary to a pancreaticoportal fistula and portal system thrombosis is described. The diagnosis was made by endoscopic retrograde cholangiopancreatography and confirmed by immediate postprocedure computed tomographic scanning. Laboratory studies identified concomitant antiphospholipid syndrome. The patient responded favourably to supportive medical therapy.

Key Words: Antiphospholipid syndrome; Pancreatic fistula; Portal vein thrombosis
Les fistules pancréaticoportales en association avec le syndrome antiphospholipidien se présentant sous forme d'ascite et de thrombose du système porte

RÉSUMÉ : La communication fistulienne entre le pancréas et le système de la veine porte est extrêmement rare et constitue généralement une complication de pancréatite chronique ou de pseudokyste pancréatique. Est décrit le cas d'un patient qui s'est présenté avec des douleurs abdominales et de l'ascite secondaires à une fistule pancréaticoportale et une thrombose du système porte. Le diagnostic a été posé au moyen d'une cholangiopancréatographie endoscopique rétrograde et a été confirmé par tomodensitométrie post-interventionnelle immédiate. Des études de laboratoire ont permis de dépister un syndrome antiphospholipidien concomitant. Le patient a réagi favorablement à un traitement d'entretien.
$\mathrm{P}_{\mathrm{c}}^{\mathrm{a}}$ ancreatic fistulas may occur as a result of chronic pancreatitis, pancreatic surgery or trauma to the pancreas (1). They are usually associated with a pancreatic pseudocyst or abscess, and most of them drain externally to form cutaneous fistulas. Ascites may develop if there is a communication between the pancreatic duct or a pseudocyst and the peritoneal cavity (2). Infrequently, a pseudocyst may erode into an adjacent organ such as the liver, spleen or stomach, or into other parts of the gastrointestinal tract (3-5). Erosion of arterial walls may lead to pseudoaneurysms, particularly of the splenic and gastroduodenal arteries, sometimes resulting in massive hemorrhage (2).

Departments of Internal Medicine and Medical Imaging, South-East Health Care Corporation, The Moncton Hospital, Moncton, New Brunswick Correspondence and reprints: Dr F Schweiger, 100 Arden Street, Suite 405, Moncton, New Brunswick E1C 4B7. Telephone 506-858-8441, fax 506-858-0859, e-mail shmills@sehcc.health.nb.ca

Received for publication March 21, 2002. Accepted June 10, 2002 


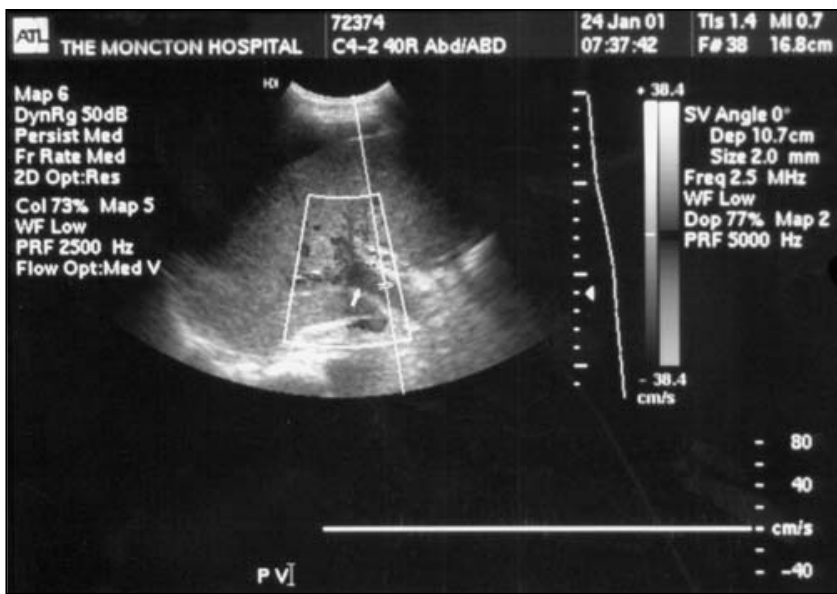

Figure 1) Doppler ultrasound demonstrating portal vein thrombosis (arrow)

Splenic vein thrombosis and subsequent portal hypertension may result from peripancreatic inflammation associated with acute attacks or from an obstructing pseudocyst (6). However, a fistulous communication between a pancreatic pseudocyst and the portal venous system is extremely rare.

We describe a patient who presented with abdominal pain and ascites. Investigations demonstrated a pancreatic pseudocyst with a fistula into the portal venous system and an underlying hypercoaguable state in the form of the antiphospholipid syndrome.

\section{CASE PRESENTATION}

A 66-year-old man was referred to the South-East Health Care Corporation, the Moncton Hospital, New Brunswick, for investigation of a pancreatic mass. He had developed acute-onset, diffuse abdominal pain and mild diarrhea one month earlier. The pain radiated to the back, was aggravated by food intake, gradually improved and became intermittent. He noticed abdominal distension, mild dyspnea and a $6 \mathrm{~kg}$ weight gain over the next three weeks. Ten days before admission, he developed fever and chills, which subsided after a one-week course of sulfamethoxazole/trimethoprim.

The patient had undergone a right femoral-popliteal bypass and external iliac endarterectomy three months before his illness. Postoperatively, he developed a large hematoma, which extended across his anterior abdominal wall, genitalia and into the left groin. On exploration of the right inguinal region, a large clot was evacuated. Some retroperitoneal bleeding was suspected but not investigated. He received $3 \mathrm{U}$ of packed red blood cells, and his hematocrit did not drop any further.

He had a history of stable exertional angina pectoris, had not smoked for 20 years and consumed four to five glasses of wine on weekends only. His medications included ramipril, acetylsalicylic acid and nitroglycerine. He was started on cimetidine at the onset of his symptoms.

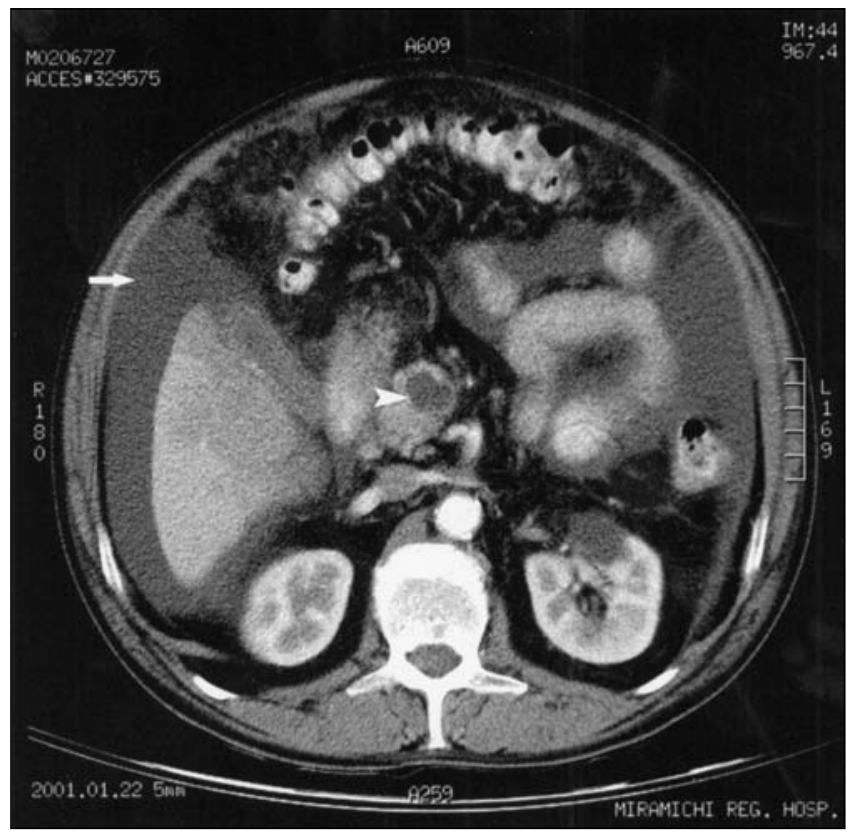

Figure 2) Computed tomographic scan showing a cystic lesion within the head of the pancreas (arrowhead) and ascites (arrow)

Clinical examination revealed an ill-looking man with a distended nontender abdomen and bulging flanks. There was no palpable mass or organomegaly.

Laboratory data were significant for the following values: white blood cell count $7.2 \times 10^{3} / \mathrm{mL}$ (normal range 4.0 to $10.0 \times 10^{3} / \mathrm{mL}$ ); hemoglobin $107 \mathrm{~g} / \mathrm{L}$ (normal range 130 to $170 \mathrm{~g} / \mathrm{L}$ ); platelet count $614,000 / \mathrm{mm}^{3}$ (normal range 150,000 to $440,000 / \mathrm{mm}^{3}$ ); erythrocyte sedimentation rate $39 \mathrm{~mm} / \mathrm{h}$ (normal range 0 to $15 \mathrm{~mm} / \mathrm{h}$ ); alkaline phosphatase $151 \mathrm{U} / \mathrm{L}$ (normal range 42 to $121 \mathrm{U} / \mathrm{L}$ ); gamma-glutamyltranferase $70 \mathrm{U} / \mathrm{L}$ (normal range 1 to $51 \mathrm{U} / \mathrm{L}$ ); amylase $442 \mathrm{U} / \mathrm{L}$ (normal range 25 to $125 \mathrm{U} / \mathrm{L}$ ); prothrombin time $14.5 \mathrm{~s}$ (normal range 10.4 to $13.8 \mathrm{~s}$ ); partial thromboplastin time $47.7 \mathrm{~s}$ (normal range 22.5 to $37.5 \mathrm{~s}$ ); albumin $29 \mathrm{~g} / \mathrm{L}$ (normal range 35 to $50 \mathrm{~g} / \mathrm{L}$ ). Serum creatinine, electrolyte, calcium, transaminases, carcinoembryonic antigen, cancer antigen 19.9 and alpha-fetoprotein levels were all normal. Two sets of blood cultures were negative. Radiological assessment with ultrasonography and Doppler studies demonstrated extensive ascites as well as complete thrombosis of the splenic and portal veins (Figure 1). There was some collateral venous flow within the porta hepatis, suggesting cavernous transformation of the portal vein. Ultrasonographically guided paracentesis yielded clear peritoneal fluid with a raised amylase level of $2330 \mathrm{U} / \mathrm{L}$ (normal less than $260 \mathrm{U} / \mathrm{L}$ ). Cultures and cytology of the aspirate were negative. Computed tomography confirmed the ultrasonographic findings and showed a localized cystic lesion within the head of the pancreas (Figure 2). Endoscopy and endoscopic retrograde cholangiopancreatography (ERCP) revealed small distal esophageal varices, congestion of the gastric mucosa and a normal looking papilla. The bile duct 


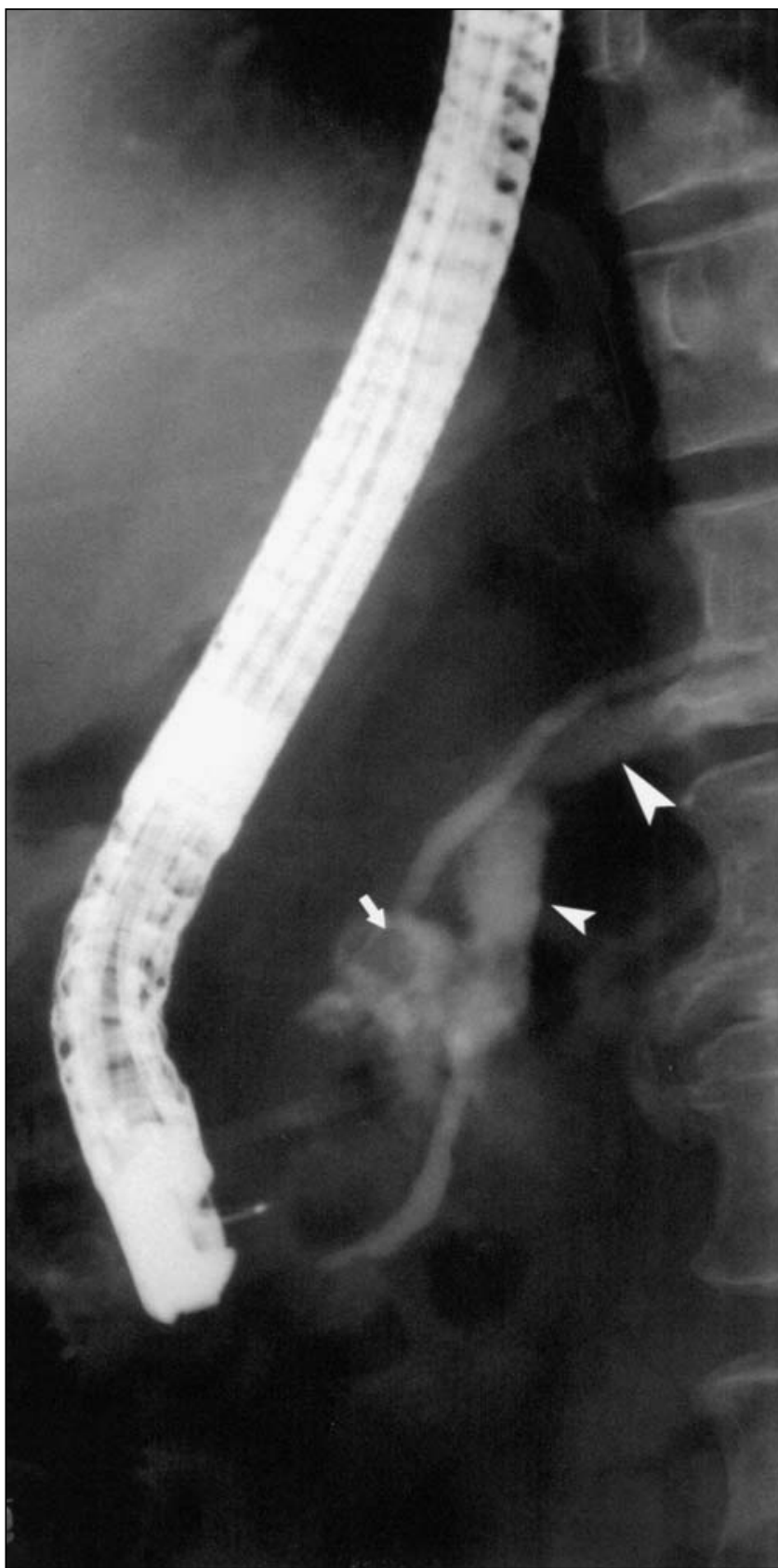

Figure 3) Endoscopic retrograde pancreatogram showing a pancreatic pseudocyst (arrow). Simultaneously the superior mesenteric (small arrowhead) and splenic veins (large arrowhead) are outlined
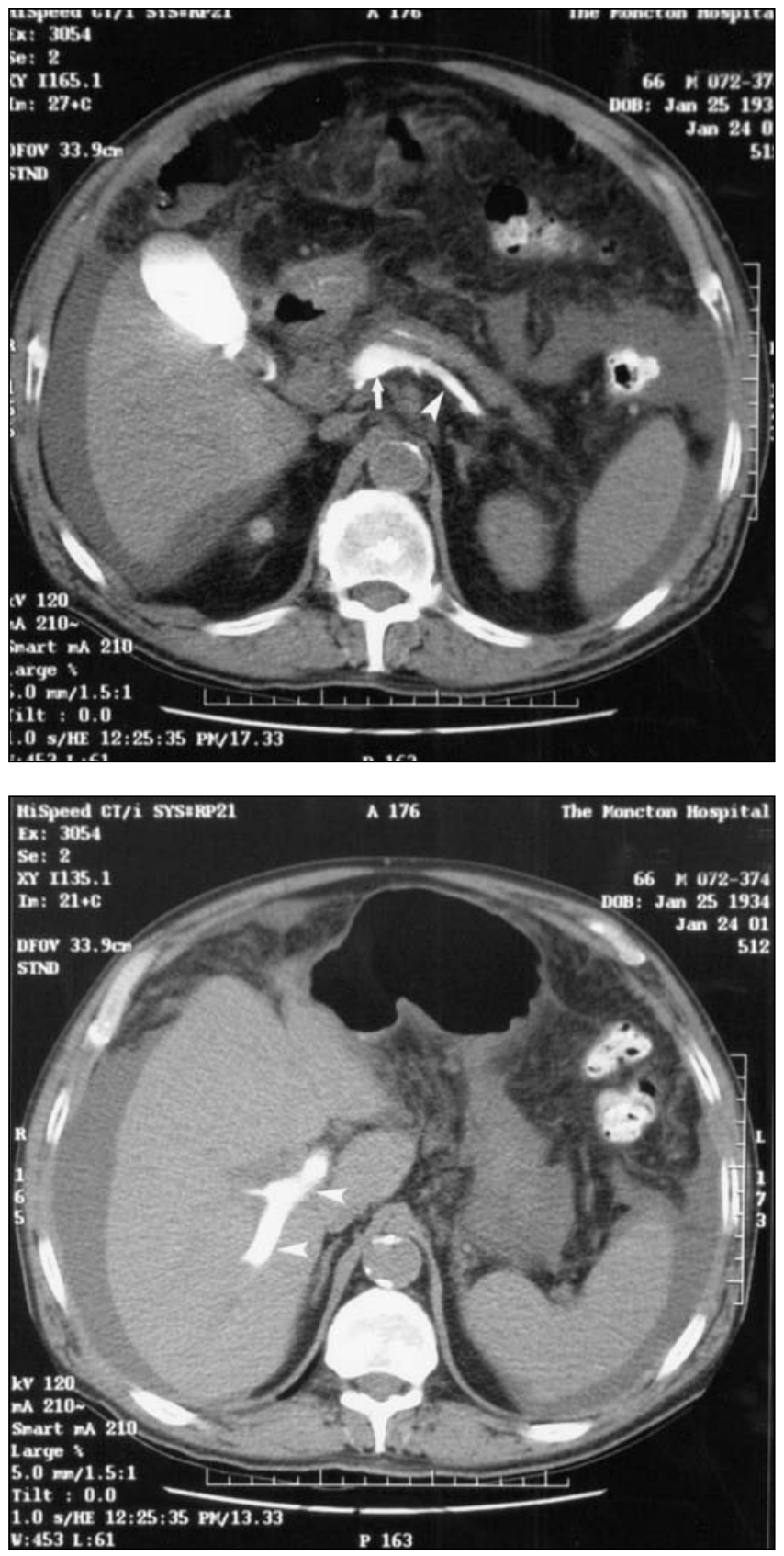

Figure 4) Computed tomographic scans obtained after endoscopic ret rograde cholangiopancreatography showing contrast in the portal vein (arrow) at its junction with the splenic vein (arrowhead) (top) and thrombus in the distal portal vein with residual contrast (arrowheads) (bottom)

tulous communication with the pancreatic duct and the extensive thrombosis within these vessels (Figure 4).

Further coagulation studies showed normal antithrombin III, protein $\mathrm{C}$, protein $\mathrm{S}$, homocysteine and alpha-2macroglobulin levels. Activated protein $\mathrm{C}$ resistance was not found. However, the anticardiolipin immunoglobulin $\mathrm{G}$ concentration was $38.4 \mathrm{GPL} / \mathrm{mL}$ (normal range 0.0 to 10.0 GPL/mL). Serological tests for antinuclear, extracted nuclear and anti-double-stranded DNA antibodies were negative. Repeat anticardiolipin immunoglobulin $G$ level 


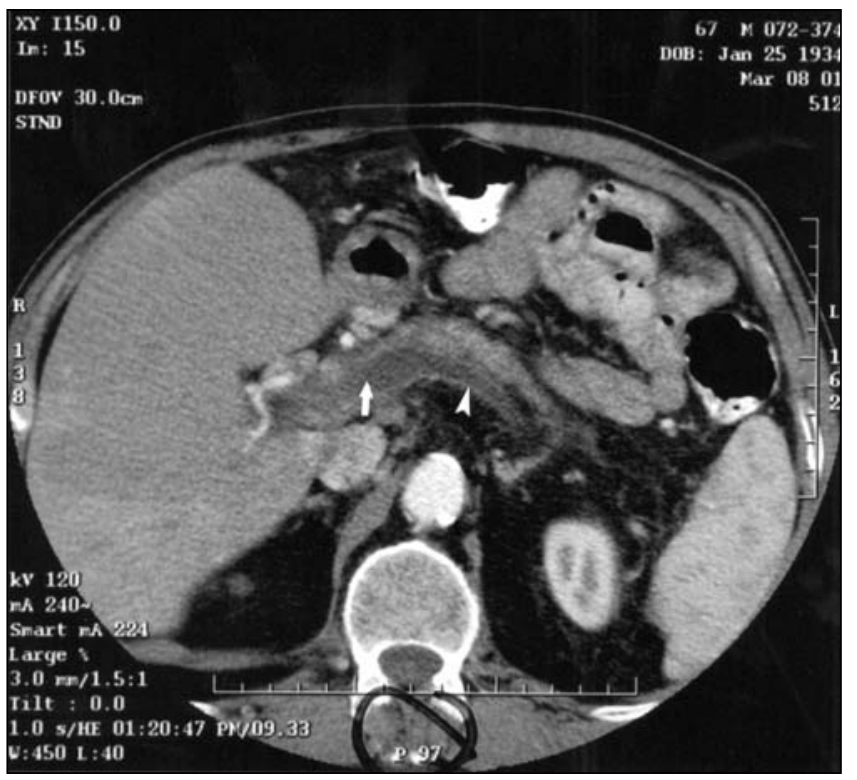

Figure 5) Computed tomographic scan showing persistent clot in the portal vein (arrow) and splenic vein (arrowhead) six weeks after the initial evaluation

measured six months later remained significantly elevated (44.8 GPL/mL), confirming the diagnosis of primary antiphospholipid syndrome.

The patient was initially treated with intravenous heparin and then switched to oral warfarin sodium. He received cefotaxime and metronidazole intravenously for 10 days and then completed a 21-day course of ciprofloxacin. During his hospitalization, $3 \mathrm{~L}$ of ascitic fluid were removed by paracentesis. A follow-up computed tomography scan six weeks after the initial evaluation showed no residual ascites, but several cystic areas within an enlarged head of the pancreas and persistent thrombosis of the portal and splenic veins (Figure 5).

\section{DISCUSSION}

Spontaneous rupture of a pancreatic pseudocyst occurs in less than 3\% of affected patients and presents either as an acute abdominal event, or as pancreatic ascites or pleural effusion (7). However, rupture of a pseudocyst into the portal circulation is distinctly unusual, with only 23 cases published since its first description in 1966 (8-27). In 17 cases, there was underlying chronic alcoholic pancreatitis, and in one patient, a pancreatic adenocarcinoma was identified at autopsy in addition to chronic pancreatitis (15). There is a single case report of a pancreatic duct-portal vein fistula that occurred in the absence of an identifiable pseudocyst (16). Although there was no previous history of chronic pancreatitis in our patient, the finding of a pseudocyst and no radiological evidence of malignancy suggest that he likely had at least chronic inflammatory changes in the head of the pancreas. The etiology of his pancreatitis is not clear, although his recent vascular surgery complicated by hemorrhage may be related.
The mechanism of pancreatic duct-portal vein fistula formation remains unknown but is likely related to the erosive action of pancreatic enzymes (23). Once a fistula has formed, the pressure gradient favours the flow of pancreatic juice from the pancreatic duct into the portal venous circulation (28). The resulting inflammatory reaction may lead to thrombosis formation. This process may have been accelerated in this unique case, in which a hypercoaguable state coexisted. Indeed, the presence of peripheral and coronary arterial disease, extensive portal system thrombosis and the finding of significantly elevated anticardiolipin antibody levels suggest concomitant antiphospholipid syndrome (29). Elevated anticardiolipin antibody levels have been associated with Budd-Chiari syndrome, superior mesenteric vein and portal vein thrombosis (30-32).

Eight of the previously reported patients with pancreatic duct-portal system fistulas developed disseminated fat necrosis in association with raised serum amylase levels $(8,9,11,14,16,18-20,27)$. It has been suggested that this is the direct result of leakage of pancreatic enzymes into the systemic circulation. Widespread portal system thrombosis may have prevented this complication in our patient.

The clinical presentation of a pancreaticoportal fistula is quite variable. Underlying chronic pancreatitis was present in all previously reported cases. Subcutaneous nodules and ascites with or without abdominal pain were the initial complaints of patients who developed disseminated fat necrosis. Other presenting features included severe abdominal pain $(10,12,15,17,23-25)$, sepsis $(16,21,22)$, hypochromic microcytic anemia with positive fecal occult blood (12), upper gastrointestinal bleeding from the papilla (23), esophageal varices $(13,15)$ and ascites (19).

Various diagnostic imaging techniques have been used to diagnose this entity, including ultrasonically guided percutaneous pancreatic ductography and transhepatic portography (12), computed tomography-guided transhepatic portography (23) and ERCP $(10,16,17,19,20,21,24,25)$. The diagnosis was made during laparotomy in two cases $(13,18)$ and at autopsy in four cases $(9,14,15,22)$. In the presence of venous thrombosis, ERCP followed immediately by computed tomography scan as performed in our patient appears to be a safe and accurate diagnostic strategy.

Reported treatments for pancreaticoportal fistula range from conservative medical management to some variation of pancreatectomy $(19,25,26)$. Because of the rarity of this complication, treatment clearly needs to be individualized. In our patient, medical treatment with prophylactic antibiotics, anticoagulation and therapeutic paracentesis led to marked clinical improvement, which persisted after a sixmonth follow-up.

\section{REFERENCES}

1. Lipsett PA, Cameron JL. Internal pancreatic fistula. Am J Surg 1992;163:216-20.

2. Pitchumoni CS, Agarwal N. Pancreatic pseudocysts: when and how should drainage be performed. Gastroenterol Clin North Am 1999;28:615-39. 
3. Okuda K, Sugita S, Tsukada E, Sakuma Y, Ohkubo K. Pancreatic pseudocyst in the left hepatic lobe: a report of two cases. Hepatology 1991;13:359-63.

4. Warshaw AL, Chesney TM, Evans GW, McCarthy HF. Intrasplenic dissection by pancreatic pseudocyst. N Engl J Med 1972;287:72-5.

5. Shatney $\mathrm{CH}$, Sosin H. Spontaneous perforation of a pseudocyst into colon and duodenum. Am J Surg 1973;126:433-8.

6. Bernades P, Baetz A, Levy P, Belghiti J, Menu Y, Fekete F. Splenic and portal venous obstruction in chronic pancreatitis. Dig Dis Sci 1992;37:340-6.

7. Lillemoe K, Yeo CJ. Management of complications of pancreatitis. Curr Probl Surg 1998;35;3-98.

8. Zellers M, Hetz HH. Rupture of a pancreatic pseudocyst into the portal vein. JAMA 1966;195:869-71.

9. Trapp R, Breuer R, Crampton A, et al. Pancreatic duct arteriovenous fistula and the metastatic fat necrosis syndrome. Dig Dis Sci $1979 ; 24: 403-8$.

10. Takayama T, Kato K, Katada N, et al. Radiological demonstration of spontaneous rupture of a pancreatic pseudocyst into the portal system. Am J Gastroenterol 1982;76:55-8.

11. Lee SH, Bodensteiner D, Eisman S, Dixon AY, McGregor DH. Chronic relapsing pancreatitis with pseudocyst erosion into the portal vein and disseminated fat necrosis. Am J Gastroenterol 1985;80:452-8.

12. Takayama T, Kato K, Sano H, Katada N, Takeichi M. Spontaneous rupture of a pancreatic pseudocyst into the portal venous system. AJR Am J Roentgenol 1986;147:935-6.

13. Pedrazzoli S, Petrin P, De Marchi L, Miotto D, Bonadimani B, Costantino V. An unusual complication of chronic pancreatitis: a recanalized portal tree communicating with a pancreatic pseudocyst. Am J Gastroenterol 1986;81:698-701.

14. Sorensen EV. Subcutaneous fat necrosis in pancreatic disease. J Clin Gastroenterol 1988;10:71-5.

15. Demetrick DJ, Kelly JK. Variceal hemorrhage as a consequence of spontaneous rupture of a pancreatic pseudocyst into the splenic vein. Am J Gastroenterol 1989;84:1103-5.

16. Willis SM, Brewer TG. Pancreatic duct-portal vein fistula. Gastroenterology 1989;97:1025-7.

17. Van Steenbergen W, Ponette E. Pancreaticoportal fistula: a rare complication of chronic pancreatitis. Gastrointest Radiol 1990;15:299-300.

18. Potts JR. Pancreatic-portal vein fistula with disseminated fat necrosis treated by pancreaticoduodenectomy. South Med J 1991;84:632-5.
19. Delcenserie R, Bental A, Goll A, Butel J, Dupas JL. Fistule pancreatico-portale et cytosteatonecrose sous-cutanee. Gastroenterol Clin Biol 1994;18:1132-7.

20. Rabache A, Crinquette JF, Vermersch A, et al. La fistule pancreaticoportale: une complcation rare de la pancreatite chronique. Gastroenterol Clin Biol 1994;18:1138-41.

21. Roussin-Bretagne S, Choury AD, Hezode C, Chochon M, Andrieu J. Fistule pancreatico-portale au cours d'une pancreatite chronique. Gastroenterol Clin Biol 1994;18:1153-4.

22. Skarsgard ED, Ellison E, Quenville N. Spontaneous rupture of a pancreatic pseudocyst into the portal vein. Can J Surg 1995;38:459-63.

23. Procacci C, Mansueto GC, Graziani R. Spontaneous rupture of a pancreatic pseudocyst into the portal vein. Cardiovasc Intervent Radiol 1995;18:399-402.

24. Lum C, Cho KC, Scholl DG, Sundaram NL. Portal vein opacification during ERCP in patients with pancreatitis. Abdom Imaging 1998;23:81-3.

25. Hastier P, Buckley MJ, Dumas R, et al. Pancreatico-portal fistula after endoscopic cystogastrostomy in chronic calcifying pancreatitis. Pancreas 1998; 17:208-10.

26. Yamamoto T, Hayakawa K, Kawakami S, et al. Rupture of a pancreatic pseudocyst into the portal venous system. Abdom Imaging 1999;24:494-6.

27. Hammar AM, Sand J, Lumio J, et al. Pancreatic pseudocystportal vein fistula manifests as residivating oligoarthritis, subcutaneous, bursal and osseal necrosis: a case report and review of literature. Hepatogastroenterology 2002;49:273-8.

28. Rolny P, Arleback A, Jarnerot GG, Andersson T. Endoscopic manometry of the sphincter of Oddi and pancreatic duct in chronic pancreatitis. Scand J Gastroenterol 1986;21:415-20.

29. Hughes $G$. The antiphospholipid syndrome: ten years on. Lancet 1993;342:341-4

30. Pelletier S, Landi B, Piette JC, et al. The antiphospholipid syndrome as the second cause of non-malignant Budd-Chiari syndrome. Arthritis Rheum 1992;35(Suppl):S238. (Abst)

31. Blanc P, Barki J, Fabre JM, et al. Superior mesenteric vein thrombosis associated with anticardiolipin antibody without autoimmune disease. Am J Hematol 1995;48:137.

32. Brady L, Magilavy D, Black D. Portal vein thrombosis associated with antiphospholipid antibodies in a child. J Pediatr Gastroenterol Nutr 1996;23:470-3. 


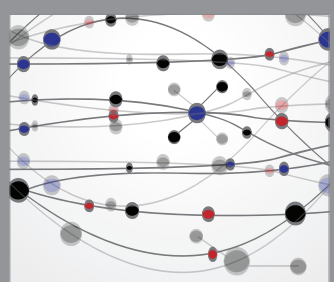

The Scientific World Journal
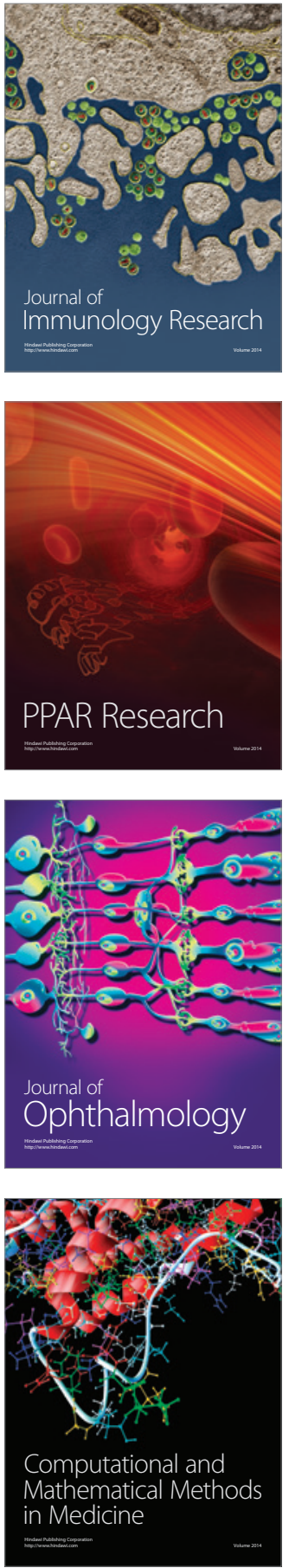

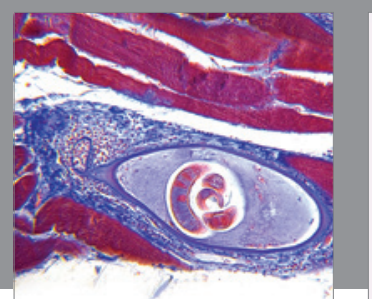

Gastroenterology Research and Practice

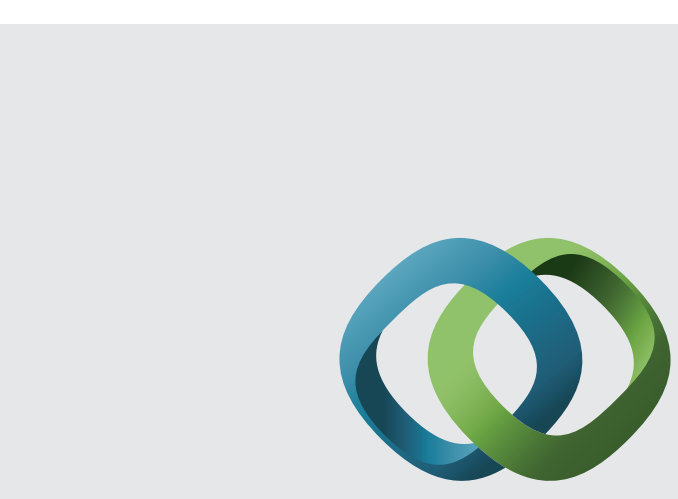

\section{Hindawi}

Submit your manuscripts at

http://www.hindawi.com
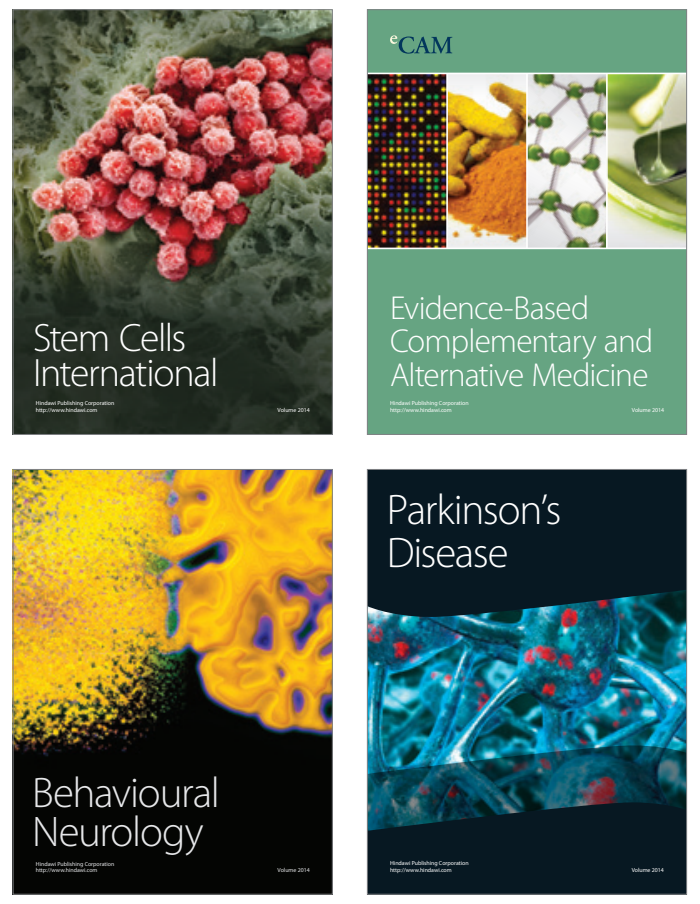
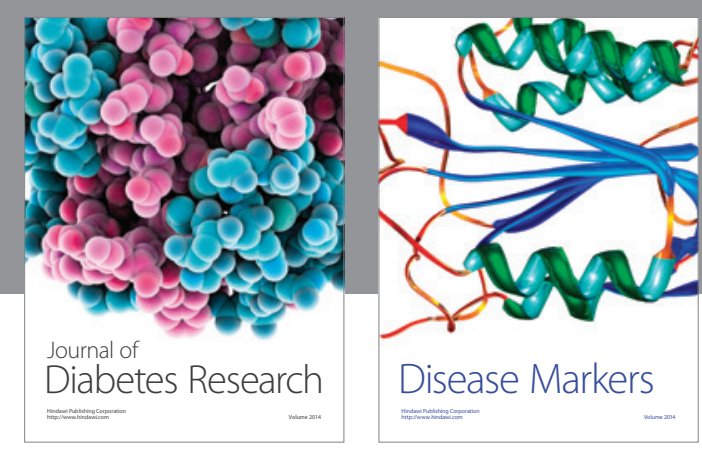

Disease Markers
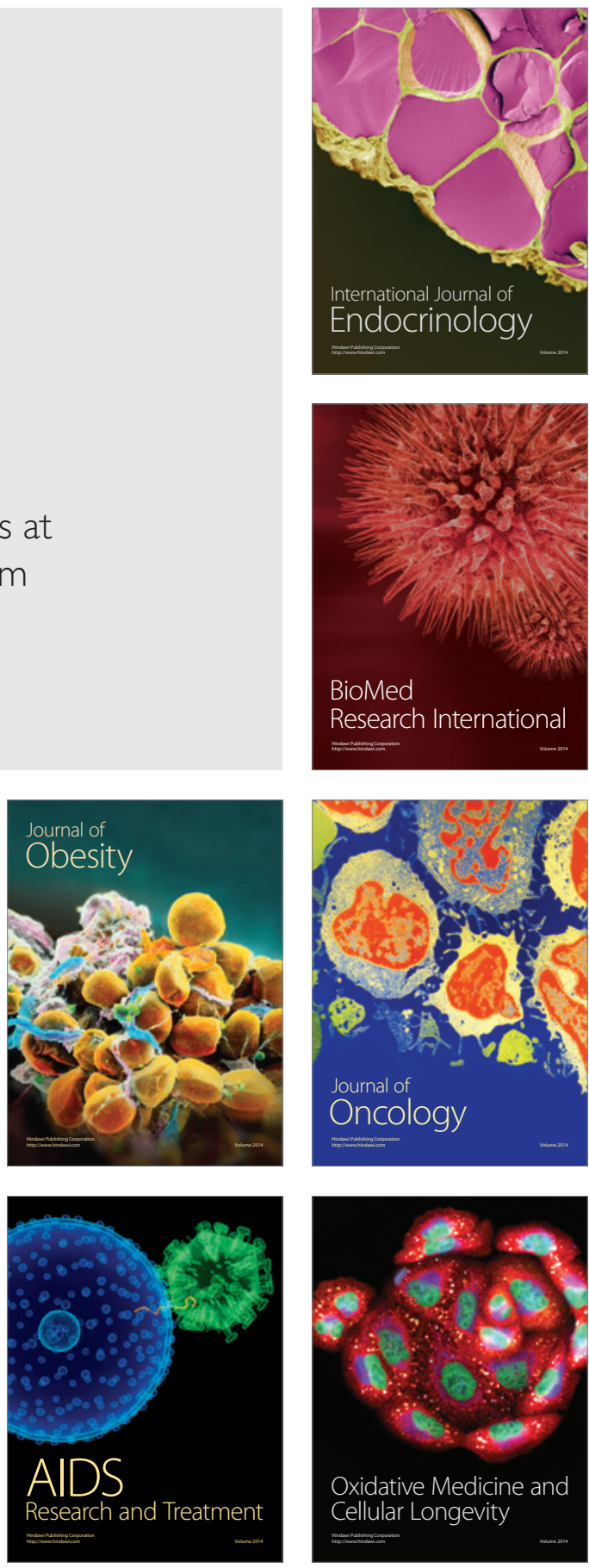